\title{
Swimming pool-based exercise as pulmonary rehabilitation for COPD patients in primary care: feasibility and acceptability
}

\author{
*Susan Rae ${ }^{a}$, Patrick White ${ }^{b}$ \\ a Community Specialist Practitioner, Sydenham Green Group Practice, Sydenham, London, UK \\ b Senior Lecturer, Department of General Practice and Primary Care, King's College London School of Medicine, London, UK
}

Originally submitted 25th July 2007; revised version received 10th April 2008; accepted 23rd June 2008; online 9th September 2008

\begin{abstract}
Aim: To assess the feasibility and acceptability of swimming pool-based exercise as pulmonary rehabilitation (PR) for COPD sufferers. Method: 101 patients with mild or moderate COPD registered with a South London general practice were invited to a swimming poolbased PR programme. Participants completed spirometry, the Chronic Respiratory Questionnaire (CRQ-SR), and the Incremental Shuttle Walk Test (ISWT) before and after the programme. A qualitative interview was used to assess participants' views.

Results: 24 patients (24\%) expressed interest; 18 were recruited and 16 (16\%) completed the PR programme. Their mean age was 69 yrs, seven were female, and mean \% predicted FEV1 was 59\%. The mean number of sessions attended was 10.6 out of 12 . Significant improvements in dyspnoea score (difference $4.9 ; 95 \% \mathrm{Cl}-8.27$ to -1.48 ) and walking distance (difference $32 \mathrm{metres} ; 95 \% \mathrm{Cl}-52.63$ to -11.36) were observed, and all other findings were in the direction of improvement. Most patients enjoyed being in the water, were happy to expose themselves in swimsuits, overcame their fears, valued learning about COPD and socialising with fellow sufferers, and were positive about their physical improvement.

Conclusion: The swimming pool is a feasible and positive alternative venue for PR for COPD patients in primary care.

(C) 2009 General Practice Airways Group. All rights reserved.

S Rae and P White. Prim Care Resp J 2009; 18(2): 90-94.

doi:10.3132/pcrj.2008.00052
\end{abstract}

Keywords COPD, pulmonary rehabilitation, exercise, swimming pool-based, feasibility, acceptibility, primary health care

\section{Introduction}

Pulmonary rehabilitation (PR) is one of the most effective interventions in improving quality of life in established chronic obstructive pulmonary disease (COPD). ${ }^{1,2}$ PR exercise usually consists of walking, cycling, gym work, or using weights to increase muscle mass. Gym-based exercises may be difficult for some patients with COPD - who tend to be mainly elderly and who may have other co-morbidities such as severe arthritis which may impair their ability to exercise at a high enough intensity. Experience in rheumatoid arthritis, heart failure, and fibromyalgia suggests that using water as the medium for exercise in PR may broaden its appeal, acceptability, and effectiveness..$^{3.5}$ In Sweden, exercise in water has been shown to induce a lower heart rate compared to the same exercise intensity on land. ${ }^{6}$ In a number of studies of hydro-therapy in a hospital setting, Kurabayashi and colleagues concluded that exercise in a hot spring-water pool may be useful in COPD. ${ }^{7-10}$ Exercise in water has characteristics that may make it beneficial in the elderly. ${ }^{11,12}$ These observations suggest that people with COPD may find exercise in water more suitable. Furthermore, in the UK, swimming pools may be more accessible venues for PR than gyms since they are open to the community.

In this study, therefore, we have assessed the feasibility and acceptability of using a swimming pool as the venue for PR exercise for COPD sufferers.

\footnotetext{
* Corresponding author: Sydenham Green Group Practice, 26 Holmshaw Close, Sydenham, London, SE26 4TH, UK.

Tel: +44 (0)7870 433256 E-mail: sneeda@hotmail.com.
} 


\section{Method}

This was an observational study carried out in two separate groups run concurrently between January and March 2006. We used a mixed qualitative and quantitative approach. Response and participation rates were assessed, and changes were sought in lung function, exercise capacity, and quality of life. Interviews were conducted with participants to assess their views of the swimming pool-based programme.

\section{Setting}

One-hundred-and-one patients with mild to moderate COPD (NICE Guidelines criteria) were identified from the practice computer disease register; they were invited by letter to attend for interview, to learn about the project, and to be assessed for their suitability to take part - including suitability for spirometry assessment. ${ }^{13}$ A stamped addressed reply envelope was provided. Respondents were offered an appointment by telephone. There was no upper age limit but patients were excluded if: they had severe COPD or were on long term oxygen therapy; had cardiac or neurological problems that would interfere with their ability to exercise; or suffered oxygen desaturation to the level of $85 \%$ or lower whilst participating in the baseline exercise capacity test. At interview eligible patients who were willing to participate gave informed consent and were offered a second appointment at which baseline assessment was carried out including: self-reported respiratory specific quality of life (CRQ-SR); oxygen saturation measurement (Nonin Onyx, Nonin Medical, model 9500); and Incremental Shuttle Walk Test (ISWT). ${ }^{14,15}$

\section{Swimming pool-based exercise programme}

This was a pulmonary rehabilitation programme of 12 sessions of exercise over six weeks (two sessions per week), which included education and social interaction. Participants were divided into two groups of nine and the two groups ran concurrently. A warm-up session was provided on land at the beginning of each exercise programme based on the British Lung Foundation (BLF) exercise diary. ${ }^{16}$ Participants then changed into swimming costumes and entered the pool to complete a half-hour exercise session. The pool temperature was $29^{\circ}$ centigrade, the standard leisure use temperature. After a further warm-up in the pool, exercises were adapted to individual participants' capacities and included upper and lower limb exercises, resistance exercises using elevation and movement against water, and endurance. A cool-down exercise was undertaken at the end. An education session covering a range of topics including disease pathology, selfmanagement, treatment, diet, breathing techniques, energy conservation, and relaxation, was given after each exercise session. Education was provided by a multidisciplinary team including a physiotherapist, doctor, specialist nurses and exercise instructor. Participants were encouraged to exercise at home in line with their individual capacities. The BLF diary was used to record their activities at home.

At the end of the final exercise session a group evaluation was conducted for each group. The group discussions were audio taped. Three questions were asked: What were the best things about the course? What was liked least about the course? What could be done differently? The interview was semi-structured with questions on perception of value of the course, swimming as exercise, participation in group activity in a swimming costume, role of education, and role of social interaction. Participants were given an appointment to attend the surgery within two weeks to repeat the shuttle walk test, the CRQ-SR, spirometry, and to complete an individual taped evaluation interview.

\section{Analysis}

The feasibility of swimming as the exercise part of the PR was assessed from the recruitment rates, participation throughout the PR programme, and from the views of the participants before and after the programme. Participants' suitability was assessed from their lung function (electronic spirometry) and respiratory specific quality of life questionnaire responses. The questionnaire assessed four domains - dyspnoea, fatigue, emotion and mastery. The results are presented as mean scores per question in each dimension. The threshold for a clinically significant change for each dimension has been previously identified as $0.5 .{ }^{17}$ Qualitative interviews conducted after the programme were audio taped, transcribed and analysed using the Framework Approach. ${ }^{18}$ Initial thematic analysis was conducted by SR. Transcripts were then read independently by PW and the themes verified.

\section{Results}

Twenty-four patients (24\%) expressed an interest in taking part. Twenty-six (26\%) did not wish to take part. Replies were not received from the remainder (50\%). Six of the 24 were excluded. Four did not meet the criteria for inclusion, one dropped out at first interview, and one was admitted to hospital. Eighteen subjects started the project, but two dropped out after the interview and assessments, leaving 16 participants ( 7 female) to start the PR program. The process of recruiting is shown in Figure 1. Mean age was 68.9 years (57-85). Mean forced expiratory volume in the first second $\left(\mathrm{FEV}_{1}\right) \%$ predicted was $58.5 \%$ (range $41-74$; standard deviation 11.6). Mean $\mathrm{FEV}_{1} /$ forced vital capacity (FEV $1 / F V C$ ) was $0.57(0.44-0.70 ; 8.7)$. The mean number of sessions attended was $10.6(4-13 ; 2.6)$. The participants were randomly assigned to two groups; the first group consisted of 3 females and 5 males (mean age 67.5 years) and the second 4 females and 4 males (mean age 71.6 years).

There were significant improvements in dyspnoea scores and walking distance between the beginning and end of the 
Figure 1. Flow diagram of recruitment to study of swimming pool-based exercise for pulmonary rehabilitation

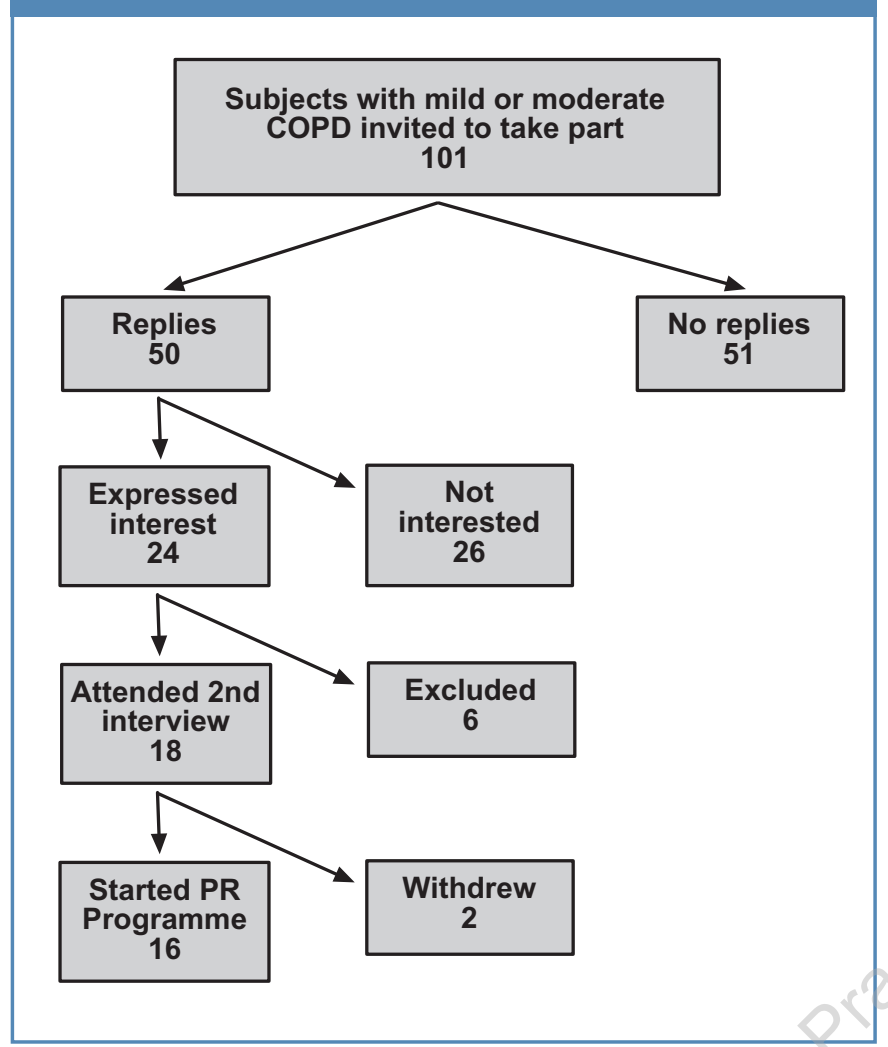

project (Table 1). All other measures were in the direction of improvement.

\section{Interview data/views of the participants.}

Being in the water - Most people who took part in the PR programme enjoyed being in the water because of the freedom the water gave them compared to the exercise they were doing on land (the warm-up), the feeling of weightlessness, and the ease of exercising in the water.
"Umm, well actually I suppose it was the camaraderie in the water, the social side, but apart from that, it didn't seem so strenuous to have to do the exercise, the exercise that we done in the water like stretching and things like that, you know, the water seems to take the weight." (Male, aged 74).

"The buoyancy, the way the umm, all your pains went away, you know, and umm, cause especially with my hip and my wrist, I found that the arthritis was gone, you know." (Female, aged 73).

Exposure in a swimsuit - Trepidation about getting into a swimming costume or a swimming pool after many years was not borne out by the experience.

"At first I was very embarrassed because I haven't been swimming, the last time I went swimming I think was when I was about 23, and I had quite a nice trim body (both laughing), so yes, I was embarrassed the first time, with all me blabber hanging around, and that yes, but after that it was fine." (Female, aged 58). "I am not a body beautiful and all that, I am not a nice sight sometimes with the scars and things but then again you know, as long as a lot of people don't mind, Idon't mind." (Male, aged 79).

"No problem, to start off with, I mean, when I got me bathing costume and I put it on and I looked at myself in the mirror, I thought no way, people would see me looking like that but then when I did put it on, and I went down to the water and I saw what other people looked like, I thought, no problem." (Female, aged 73).

Fear of the water - A few of the participants who had a fear of the water before they started the course overcame these fears.

"Umm, exercise is very good, swimming, very good but I panic a bit, I still do, occasionally, I mean, I did yesterday."

Table 1. Outcome of pulmonary rehabilitation using a swimming pool-based exercise programme (paired t-tests; $n=16)$.

\begin{tabular}{ccccc} 
& Before & After & Difference & $95 \%$ confidence interval \\
\hline $\mathrm{FEV}_{1}$ & 1.6 & 1.6 & -0.03 & -0.16 to -0.1 \\
\hline $\mathrm{FEV} / \mathrm{FVC}$ & 2.8 & 2.9 & -1.58 & -0.34 to 0.02 \\
\hline $\begin{array}{c}\text { Quality of life (CRQ-SR) } \\
\text { Dyspnoea }\end{array}$ & 15.6 & & -4.9 & -8.27 to -1.48 \\
$\quad$ Emotion & 30.5 & 20.3 & -4.31 & -10.56 to 1.94 \\
Fatigue & 14.9 & 34.5 & -1.88 & -4.63 to 0.88 \\
Mastery & 17.8 & 16.8 & -2.44 & -6.19 to 1.31 \\
\hline ISWT * $(n=15)$ & 292 & 20.2 & -32.00 & -52.63 to -11.36 \\
\hline
\end{tabular}

*One of the participants had injured his back, could not complete the ISWT following the PR program and was excluded from this element of the analysis. Six months after the end of the programme 8 participants continued to swim twice-weekly at the leisure centre. 
"Yes, yes it does, I mean when I first went, I couldn't put my face in the water, but now I can put my head in the water." (Female, aged 68)

"I used to swim before the course but I stopped because I had a bad chest I panicked in the water." (Male, aged 78).

Education - the educational component of PR was acknowledged as a useful element.

"Only if you get all you know, excited and something when your breathing is bad is to more or less sit and breathe very steady like." (Female, aged 73).

"I think I could cope with it having listened to different talks that we had and I can cope with it in as much as now I wouldn't panic, whereas before I would probably get all scared and start doing silly breaths instead of deep breaths but umm, I don't think I would have any problems, no." (Female, aged 73).

"Umm, I enjoyed, as I said earlier about being told how to breathe correctly and to do these exercises, I mean, it was very informative and I really feel that lots of other people will benefit by this." (Male, aged 59).

Socialising - Meeting others with COPD benefited most participants.

"Well because you can talk about it different things that we didn't know before, go over, I think one says, "oh I didn't realise that", you can, you know, one remembers one thing and somebody else would remember something else, that was quite good." (Female, aged 73).

"You find that there is other people with the same problems as you, you are able to talk to each other about them, and it makes you feel less isolated, umm, you know, that sort of thing" (Female, aged 58).

"Yes I did, I mean it just proved to me, I mean, cause it's very isolating, I mean, you go to your doctor, your doctor says you got this, what's that, and you go away and you are kind of, you are on your own, you have got your friends that you socialise with and they don't talk about it, you don't talk about it and suddenly you are thrown with 8 or 10 other people who are suffering the same as you are, yes I enjoyed that, I think that's very important for fellow suffers especially if they are local because we are all local too actually, you can see them bonding and they are still bonding today." (Male, aged 59).

Impact on well being - Many reported an improvement in physical well being.

"Oh I feel a lot better physically, yes; at least I don't get so tired." (Male, aged 74).

"I feel fitter and brighter." (Male, aged 78).

"I still need the medication, I have felt ever such a lot better with me breathing, I walk about the house more, and I walk up and down stairs more." (Female, aged 73).

"A bit more energy, a bit more awake." (Female, aged 58).

"Even after the first day, I was feeling I had been using something that I hadn't use in yonks." (Male, aged 64).

\section{Discussion}

This study shows that a swimming pool is a feasible and acceptable venue for the exercise component of pulmonary rehabilitation for patients with mild or moderate COPD in primary care. One in six primary care patients with mild or moderate COPD from one general practice completed the swimming pool-based exercise programme after one in four patients had expressed interest in the programme. Significant improvement in dyspnoea scores and walking distance were observed and all other findings were in the direction of improvement. All participants evaluated the programme as good or very good. They enjoyed meeting other people with COPD, learnt more about their condition, and felt better about it. Half of the people who attended had continued to exercise in water twice-weekly six months after the programme ended.

This study was conducted in one large general practice in the UK. The findings cannot be generalised to all primary care teams. However, one of the strengths of this feasibility study lies in the inclusion of all patients with mild or moderate COPD on the practice's COPD register and the use of the local swimming pool. The conduct of the full range of interventions and assessments normally used in studies of pulmonary rehabilitation confirm the suitability of this approach for a clinical trial. It is not known if the participation rate was more or less than might be expected in conventional pulmonary rehabilitation in such a population. There is no comparable study of pulmonary rehabilitation offered to every subject with mild or moderate COPD on a practice's list. Jones et al recruited 14 (47\%) of 30 subjects (FEV 1 less than $60 \%$ predicted) who were more severely affected than subjects in this study. ${ }^{19}$ In an even more severely affected group (FEV $130-50 \%$ predicted) Ward et al recruited 28 of 34 subjects invited of whom 27 (79\%) completed the programme. ${ }^{20}$ In neither of these studies were all potentially suitable subjects identified from the participating practices' registers and used as the baseline denominator.

The inclusion of a qualitative study of the experience of participants is a notable strength of this study. The standard components of pulmonary rehabilitation (exercise, education, and social interaction) were well received. The exceptional circumstances of the exercise, including exercise in swimming costumes in a group, entry into the water, and immersion in 
water, were all welcomed and noted as significant elements of the sense of achievement associated with participation.

The effect of exercise in a swimming pool was not compared with conventional pulmonary rehabilitation. However, the significant improvement in dyspnoea score after the programme, and the positive trend in all the evaluations support the conduct of a rigorous randomised controlled trial of swimming pool-based pulmonary rehabilitation.

There is a growing interest in PR in primary care and this study confirms the potential for recruiting subjects with mild and moderate COPD. The evidence of benefit from PR in COPD is undisputed. Early intervention may be important in improving quality of life and education about this chronic disease. However, there is a relatively poor understanding of the particular role of the exercise component, the elements of exercise that are essential to maximising the effect of PR, and how those elements can be interchanged with other approaches or modified by them. ${ }^{21-23} \mathrm{~A}$ small body of research has examined the physiological effects of exercise in water for people with respiratory diseases. ${ }^{6,10}$ Reported benefits need to be assessed in greater depth, but they are supported by the findings of this study.

In summary, exercise in water is a feasible alternative form of pulmonary rehabilitation for sufferers of mild to moderate COPD in primary care.

\section{Funding}

Funding was provided by Lewisham Research Unit, Lewisham, London.

\section{Ethical Approval}

Ethical approval was given by The Lewisham Hospital NHS Trust Research Ethics Committee.

\section{Competing interests}

None declared.

\section{Acknowledgements}

We thank the staff and patients of Sydenham Green Group Practice in south-east London, Susan Robinson and Anthony Theuninck of Lewisham Research Unit, Amy Grant of King's College Hospital Respiratory Physiotherapy Team, Tim Hector (Sports and Leisure Services, Lewisham Council), David Curtis, Carol Bobb, and Jim Sikorski.

\section{References}

1. Lacasse $Y$, Goldstein R, Lasserson TJ, Martin S. Pulmonary rehabilitation for chronic obstructive pulmonary disease. Cochrane Database Syst Rev 2006;(4):CD003793. http://dx.doi.org/10.1002/14651858.CD003793.pub2

2. Nici L, Donner C, Wouters E, et al. American Thoracic Society/European Respiratory Society statement on pulmonary rehabilitation. Am J Respir Crit Care Med 2006;173(12):1390-413. http://dx.doi.org/10.1164/rccm.2005081211ST

3. Eversden L, Maggs F, Nightingale P, Jobanputra P. A pragmatic randomised controlled trial of hydrotherapy and land exercises on overall well being and quality of life in rheumatoid arthritis. BMC Musculoskelet Disord 2007;8:23.

4. Municino A, Nicolino A, Milanese $M$, et al. Hydrotherapy in advanced heart failure: the cardio-HKT pilot study. Monaldi Arch Chest Dis 2006;66(4):247-54.

5. Gowans SE, deHueck A. Pool exercise for individuals with fibromyalgia. Curr
Opin Rheumatol 2007;19(2):168-73. http://dx.doi.org/10.1097/ BOR.0b013e3280327944

6. Wadell K, Sundelin G, Henriksson-Larsen K, Lundgren R. High intensity physical group training in water - an effective training modality for patients with COPD. Respir Med 2004;98(5):428-38. http://dx.doi.org/10.1016/j.rmed.2003.11.010

7. Kurabayashi H, Kubota K, Tamura J. [Physical therapy in a pool as rehabilitation for chronic obstructive pulmonary disease in the elderly]. Nippon Ronen Igakkai Zasshi 1997;34(10):803-08.

8. Kurabayashi H, Machida I, Yoshida Y, Tamura J, Itoh K, Kubota K. Clinical analysis of breathing exercise during immersion in 38 degrees $C$ water for obstructive and constrictive pulmonary diseases. J Med 1999;30(1-2):61-6.

9. Kurabayashi H, Machida I, Handa H, Akiba T, Kubota K. Comparison of three protocols for breathing exercises during immersion in 38 degrees $C$ water for chronic obstructive pulmonary disease. Am J Phys Med Rehabil 1998; 77(2):145-8. http://dx.doi.org/10.1097/00002060-199803000-00012

10. Kurabayashi H, Kubota K, Machida I, Tamura K, Take H, Shirakura T. Effective physical therapy for chronic obstructive pulmonary disease. Pilot study of exercise in hot spring water. Am J Phys Med Rehabil 1997;76(3):204-07. http://dx.doi.org/10.1097/00002060-199705000-00008

11. Chu KS, Rhodes EC. Physiological and cardiovascular changes associated with deep water running in the young. Possible implications for the elderly. Sports Med 2001;31(1):33-46. http://dx.doi.org/10.2165/00007256-200131010-00003

12. Broman G, Quintana M, Lindberg T, Jansson E, Kaijser L. High intensity deep water training can improve aerobic power in elderly women. Eur J Appl Physiol 2006;98(2):117-23. http://dx.doi.org/10.1007/s00421-006-0237-2

13. National Collaborating Centre for Chronic Conditions. Chronic obstructive pulmonary disease. National clinical guideline on management of chronic obstructive pulmonary disease in adults in primary and secondary care. Thorax 2004;59 Suppl 1:1-232.

14. Poulain M, Durand F, Palomba B, et al. 6-Minute Walk Testing Is More Sensitive Than Maximal Incremental Cycle Testing for Detecting Oxygen Desaturation in Patients With COPD. Chest 2003;123(5):1401-07. http://dx.doi.org/10.1378/ chest.123.5.1401

15. Williams JE, Singh SJ, Sewell L, Guyatt GH, Morgan MD. Development of a selfreported Chronic Respiratory Questionnaire (CRQ-SR). Thorax 2001; 56(12):954-9. http://dx.doi.org/10.1136/thorax.56.12.954

16. British Lung Foundation. Exercise Diary. 2005. London, British Lung Foundation.

17. Williams JE, Singh SJ, Sewell L, Morgan MD. Health status measurement: sensitivity of the self-reported Chronic Respiratory Questionnaire (CRQ-SR) in pulmonary rehabilitation. Thorax 2003;58(6):515-18. http://dx.doi.org/10.1136/ thorax.58.6.51

18. Ritchie J, Spencer L. Qualitative data analysis for applied policy research. In: Bryman A, Burgess RG, editors. Analyzing qualitative data.London: Routledge; 1994.

19. Jones RC, Copper S, Riley O, Dobbs F. A pilot study of pulmonary rehabilitation in primary care. Br J Gen Pract 2002;52(480):567-8.

20. Ward JA, Akers G, Ward DG, et al. Feasibility and effectiveness of a pulmonary rehabilitation programme in a community hospital setting. $\mathrm{Br} J \mathrm{Gen}$ Pract 2002;52(480):539-42.

21. Koppers RJ, Vos PJ, Boot CR, Folgering HT. Exercise performance improves in patients with COPD due to respiratory muscle endurance training. Chest 2006;129(4):886-92. http://dx.doi.org/10.1378/chest.129.4.886

22. Porszasz J, Emtner M, Goto S, Somfay A, Whipp BJ, Casaburi R. Exercise training decreases ventilatory requirements and exercise-induced hyperinflation at submaximal intensities in patients with COPD. Chest 2005;128(4):2025-34. http://dx.doi.org/10.1378/chest.128.4.2025

23. Behnke M, Wewel AR, Kirsten D, Jorres RA, Magnussen H. Exercise training raises daily activity stronger than predicted from exercise capacity in patients with COPD. Respir Med 2005;99(6):711. http://dx.doi.org/ 10.1016/j.rmed.2004.10.016 